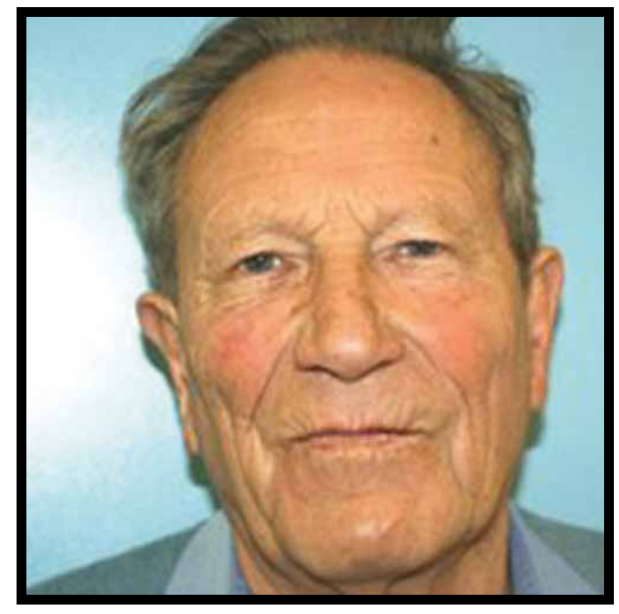

Photo from: researchgate.net

\title{
I Obituary. In memory of Professor Jon van Rood
}

Professor Jon van Rood passed away on 21 July 2017 in Leeuwarden. His research was dedicated to immunology and transplantation science. Being a Professor at the Leiden University, he was a worldwide recognized founder of tissue immunology and HLA testing in clinical transplantation.

Johannes J. van Rood was born in 1926 in Scheveningen (The Netherlands). He studied medicine at the University of Leiden and in 1957 became the head of the Immunohematology Department and the Blood Bank of Leiden University Hospital. After achieving a Doctor's title in 1962, he trained a year at the Immunology Department in the Public Health Research Institute (New York). Then he returned to Leiden, where he was appointed a Professor of Internal Medicine in 1969. Since 1976 he was Director of the Hematology Department, the Leiden University Hospital. He was among founders of the Leiden Institute for Immunology.

Professor Jon van Rood made his main successful research while discovering and classifying the genetically determined human leukocyte compatibility system (HLA membrane proteins). This discovery was made just in right time, because of difficult immunological problems that remained barriers to the progress of clinical transplantation in 60's. Being active in clinical transfusion medicine, Jon van Rood suggested collection and studying blood sera samples from pregnant women. Due to common maternal immunization by fetal antigens, a variety of specific anti-HLA antibodies are induced which have became a useful tool for detection of well-matched donor-recipient pairs in organ and tissue transplantation. Extensive collaborative studies that used standardized panels of sera and leukocyte samples using in vitro cytotoxity assays. Later on, these test systems were largely replaced by more precise PCR-based DNA testing. Such an approach enabled Professor Jon van Rood and his co-researchers to discover several different antigens of the HLA system.
Numerous data on HLA variability, upon their accumulation, required a systematic analysis. Professor Jon van Rood pioneered in computer-assisted analysis of the multifactorial tissue antigen system. This research was seminal to extensive research programs in fundamental and clinical immunogenetics, and development of big HLA-typing industry. Standardized typing of individual HLA sets proved to be indispensable for matching patients and donors for transplants, as well as blood transfusions in some special clinical situations. Furthermore, using HLA typing, Professor Jon van Rood performed the first HLA-matched platelet transfusions and developed routine leukocyte depletion as a means to prevent HLA alloimmunization.

The studies on HLA antigens required large international efforts for collection of wast experimental results and big data analysis. Professor Jon van Rood was an excellent organizer of international programs, providing a support with launching over thirty tissue-typing laboratories worldwide.

Moreover, HLA typing has paved new ways in studying the relations between HLA genotypes and predisposition towards distinct diseases, especially, autoimmune disorders. Appropriate clinical associations were obtained for some HLA genotypes but the reasons for such susceptibility are still to be cleared.

In 1967 Professor Jon van Rood founded the Eurotransplant organization, and in 1985, the European Foundation for Immunogenetics, becoming a key member of these organizations. Eurotransplant is a well known organization, now aimed for promotion and coordinating organ transplants, search for the best possible donors for kidney and other organ transplants. He also founded the Europdonor Foundation in 1970 (for bone marrow donation), Eurotissue for tissue transplantation (1987) as well as the World Marrow Donor Association in 1994. 
Jon van Rood was among key persons who founded European group for Bone Marrow Transplantation in 1974 which, over last 40 years, has evolved to the widely known European Society for Blood and Marrow Transplantation which coordinates many aspects of hematopoietic stem cell transplantation.

For his achievements, Professor Jon van Rood received a lot of international honorary awards, including several Doctor honoris causa degrees, as well as honorary prizes recognizing his scientific merits. In 1977, Jon van Rood, together with Prof. Dausset, was awarded the Robert Koch Prize. He was also awarded the Wolf Prize in Medicine, jointly with George D. Snell and Jean Dausset, "for his contribution to the understanding of the complexity of the HLA system in man and its implications in transplantation and in disease". Dr. A. H. Heineken Prize for Medicine was awarded to Johannes van Rood in 1990. He retired from his university position in 1991 but remained active researcher and lecturer.

Professor Jon van Rood's work was characterized by the unique way in which he combined scientific medical research with great value of these studies for practical medicine, especially transplantation of solid organs and hematopoietic tissues. He founded a school of transplantation immunologists who are now working in various countries.
Jon van Rood will be always nominated among founders of modern transplantation immunology. He did a lot to promote activity of young workers in this area by providing them with research and travel grants. Since 2010, the Jon van Rood prize was established by the European Blood and Marrow Transplant Group for best studies in the field of transplantation immunology. He did not limit his activities by America and Western Europe. When visiting Russia in early 90's, he consulted Russian immunohematologists in order to arrange a National Bone Marrow Donor Registry. Over last years, this idea is implemented as a working united registry with a hub in St. Petersburg, cooperating with appropriate registries in Russia and Kazakhstan: (Moscow, Kirov, Chelyabinsk, Rostov on Don, Ekaterinburg, Samara, Kazan' and Astana).

Being a widely educated and intellectually curious person, Professor Jon van Rood brought new insights and impressions from his travels and journeys. We remember his interest to St. Petersburg, Russian culture when traveling to Valaam and Kizhi in 1992.

As a bright intellectual and organizer of science, he will be remembered for many years as an example to follow for next generations of scientists working in biology and medicine.

\section{Professor Boris V. Afanasyev,}

Director, Raisa Gorbacheva Memorial Institute of Children Oncology, Hematology and Transplantation at the First State I. Pavlov Medical University

\section{| Некролог. Памяти профессора Йона Ван Роода}

Профессор Йон ван Роод скончался 21 июля 2017 г. в Леувардене (Нидерланды). Его исследования были посвящены иммунологии и науке о трансплантации. Он был профессором университета Лейдена (Нидерланды) и был всемирно признанным основателем тканевой иммунологии и тестирования антигенов HLA в клинической трансплантологии.

Йон ван Роод родился в 1926 г. в Схевенингене (Нидерланды). Он учился медицине в Лейденском университете и в 1957 г. стал главой департамента иммуногематологии и банка крови университетского госпиталя в Лейдене. После получения звания доктора в 1962 г. он 1 год стажировался в Научном институте общественного здоровья (Нью-Йорк). Затем он вернулся в Лейден, где в 1969 г. стал профессором по специальности «внутренние болезни». С 1976 г. он был директором Департамента гематологии Лейденского университетского госпиталя, был в числе основателей Лейденского института иммунологии.

Профессор Йон ван Роод провел свою главную научную работу, когда открыл и классифицировал генетически обусловленную систему совместимости человеческих лейкоцитов (HLA-антигены). Это открытие было сделано как раз вовремя, из-за сложных иммунологических проблем, которые были барьером на пути прогресса клинической трансплантологии в 60-х годах прошлого века. Будучи активен в клинической трансфузиологии, Йон ван Роод предложил собирать и исследовать образцы сыворотки крови от беременных женщин. Из-за частой иммунизации фетальными антигенами, индуцируется большое разнообразие специфических анти-HLA антител, которые можно далее классифицировать и использовать для выявления совместимых пар «донор-реципиент» при трансплантации органов и тканей. Проводились обширные совместные исследования с использованием стандартизированных панелей сывороток и образцов лейкоцитов, и тестов на цитотоксичность in vitro. Позже эти биологические тесты были дополнены более специфичным ДНК-тестированием, основанным на методиках ПЦР. Такой подход позволил профессору ван Рооду и его сотрудникам открыть несколько различных типов HLA. Многочисленные данные об антигенах совместимости, по мере накопления информации, потребовали систематического анализа. Профессор ван Роод был в числе первых, кто использовал компьютерный анализ многофакторной системы тканевых антигенов. Это исследование было основополагающим в обширных исследовательских программах фундаментальной и клинической иммуногенетики, и в развитии крупной индустрии HLA-типирования. Стандартизированное типирование индивидуальных 
наборов генов HLA оказалось незаменимым методом подбора пациентов и доноров для трансплантаций, а также для гемотрансфузий в ряде особых клинических ситуаций. Кроме того, профессор ван Роод провел первые HLA-совместимые трансфузии тромбоцитов и разработал рутинные способы деплеции лейкоцитов для предотвращения HLA-аллоиммунизации.

Изучение системы HLA потребовало обширных международных усилий, направленных на сбор экспериментальных результатов и обработку больших массивов данных. Профессор Йон ван Роод был превосходным организатором международных программ, обеспечив разнообразную поддержку при создании более 30 лабораторий по типированию тканевой совместимости по всему миру.

Кроме того, типирование HLA проложило новые пути в изучении соотношений между генотипами HLA и предрасположенностью к различным заболеваниям, в особенности - аутоиммунным синдромам. Соответствующие клинико-генетические ассоциации получены для ряда HLA-генотипов, но причины такой предрасположенности еще следует выяснить в дальнейшем.

В 1967 году профессор Йон ван Роод основал организацию «Евротрансплант», в 1985 г. - Европейский фонд иммуногенетики, став одним из ключевых участников этих организаций. «Евротрансплант» является известной организацией, направленной на поддержку и координацию органной трансплантации, поиска наиболее совместимых доноров для трансплантации почек и других органов. Ван Роод также основал Фонд «Евродонор» в 1970 г., предназначенный для донорства костного мозга, «Eurotissue» для задач тканевой трансплантации (1987), и, наконец, Всемирную Ассоциацию доноров костного мозга в 1994 году. Для нас наиболее важно то, что Йон ван Роод был среди главных основателей Европейской группы трансплантации костного мозга в 1974 году. За последние 40 лет она стала широко известным Европейским обществом трансплантации крови и костного мозга (ЕВMT), которое теперь координирует многие аспекты трансплантации гемопоэтических стволовых клеток.

За свои заслуги профессор Йон ван Роод был удостоен множества международных почетных наград, в том числе - званий почетного доктора, а также научных премий в знак признания его научных заслуг.

\section{Профессор Борис В. Афанасьев,}

директор НИИ детской онкологии, гематологии и трансплантологии им. Р. М. Горбачевой Первого Санкт-Петербургского государственного медицинского университета им. И. П. Павлова награжден премией Роберта Коха. Он был также удостоен премии Вольфа по медицине вместе с Дж. Снеллом и Ж. Доссе «За вклад в познание сложности системы HLA у человека и его приложений в трансплантологии и при заболеваниях», премии Ф. Х. Хайнекена по медицине в 1990 г. Профессор ван Роод ушел в отставку со своей университетской должности в 1991 г., но оставался активным исследователем и лектором.

Работы профессора ван Роода характеризуются уникальным сочетанием фундаментальных медицинских исследований с большой ценностью этих исследований для клинической медицины, в частности - трансплантации органов и гемопоэтических тканей. Он основал школу иммунологов-трансплантологов, которые теперь работают в разных странах.

Йона ван Роода всегда будут называть в числе основателей современной трансплантационной иммунологии. Он сделал многое для поддержки активности молодых ученых в этой области, обеспечивая им гранты на пребывание и исследования. С 2010 г., ЕВМТ учреждена ежегодная премия ван Роода за лучшие исследования в области трансплантационной. Он не ограничивался деятельностью в Америке и Западной Европе. Так, при посещении России в начале 90-х годов, он много консультировал российских иммуногематологов, чтобы организовать Национальный Регистр доноров костного мозга. За последние годы эта идея претворена в работающий единый регистр с базой в Санкт-Петербурге, работающий в кооперации с аналогичными регистрами в России и Казахстане (Москва, Киров, Челябинск, Ростов-на Дону, Екатеринбург, Самара, Казань и Астана).

Будучи широко образованным и любознательным человеком, профессор Йон ван Роод любил получать новые впечатления от путешествий и поездок. Мы помним его интерес к Санкт-Петербургу и русской культуре при поездке на остров Валаам и в Кижи в 1992 г.

Мы будем многие годы вспоминать Йона ван Роода, яркого интеллектуала и организатора науки, как пример для будущих поколений ученых, работающих в биологии и медицине.
В 1977 г. Йон ван Роод вместе с профессором Доссе был 